\title{
Inter-organizational interaction in public and private sectors - a comparative study
}

Ulf Melin and Karin Axelsson

\section{Linköping University Post Print}

\section{Tweet}

N.B.: When citing this work, cite the original article.

This article is (C) Emerald Group Publishing and permission has been granted for this version to appear here:

Ulf Melin and Karin Axelsson, Inter-organizational interaction in public and private sectors a comparative study, 2013, Transforming Government: People, Process and Policy, (7), 4, 431-452. http://dx.doi.org/10.1108/TG-07-2013-0018

Emerald does not grant permission for this article to be further copied/distributed or hosted elsewhere without the express permission from Emerald Group Publishing Limited.

Postprint available at: Linköping University Electronic Press

http://urn.kb.se/resolve?urn=urn:nbn:se:liu:diva-100141 


\section{Inter-organizational Interaction in Public and Private Sectors - A Comparative Study ${ }^{1}$}

Purpose - This article compares inter-organizational (IO) interaction and inter-organizational information systems (IOS) to support IO interaction in public and private sectors. The purpose of the article is to explore and discuss differences and similarities between e-government and e-business focusing IOS and interaction. This is done in order to facilitate learning between the two fields. The point of departure is two case studies performed in private and public sectors.

Design/Methodology/Approach - A comparative study of two cases in two sectors (private and public) is conducted. IO concepts from industrial markets that characterize an IO relationship (continuity, complexity, symmetry, and formality) and concepts that describe dimensions of such relationships (links, bonds, and ties) are used as analytical lenses. The empirical case study data, mainly generated from interviews, has been analyzed in a qualitative, interpretive way, using these central IO concepts from industrial markets (The IMP approach). This approach is in line with a strategy to use theory as a part of an iterative process of data collection and analysis.

Findings - The findings in the present study show that there are several similarities concerning interaction in relations between organizations in the two sectors. There are also differences depending on the level of analysis (empirical level vs. analytical level). The study shows the need to be explicit regarding organizational value, endcustomer or client/citizen value and the type of objects that are exchanged in the interaction. This is presented in the article together with suggested refinements of the analytical framework used for understanding IO interaction. The latter finding is a contribution to the general field of interaction and network studies and also a contribution to the e-government field.

Research limitations/implications - This research provides understanding of similarities and differences in the two sectors when analyzing IO interaction and IOS. The study also illustrates a systematic way of analyzing and comparing IO interaction and IOS use in different sectors. However, it is also urgent to learn more about IO interaction between a private and a public organization and how it would be beneficial for understanding both sectors. The issue of trust is an important aspect that is embedded in the IMP approach used in this article. Further understanding of IO interaction can be reached by applying research focused on trust as such. Thus, the findings call for more studies in the area of inter-sector learning, IO interaction and e.g. trust.

Practical implications - This article is a point of departure to facilitate learning between the public and the private sectors focusing on IO relations and IOS. Learning between the two sectors is needed for researchers in the two areas as well as policy makers and practitioners developing e.g. e-government interaction and IOS.

Originality/value - There are few articles addressing learning between the private and the public sector within the e-government area. Not at least when focusing inter-organizational issues. There is also a tendency that wheels are reinvented in the sectors and in the e-government research area. An important initiative in this article is to contribute in filling this gap by providing examples of a comparative analysis as well as understanding of how to perform such analyses of IO interaction.

Keywords - B2B, G2G, interaction, e-government, e-business, inter-organizational, IO, IOS.

Paper type - Research paper

\section{Introduction}

Inter-organizational (IO) interaction, relations and processes are central in all organizational development regardless of sector, with or without information systems (IS) development in parallel. Inter-organizational information systems (IOS) have been on the research agenda for almost 30 years (Goodhue et al., 1992; Cavaye and Cragg, 1995; Kumar and van Dissel, 1996; Robey et al., 2008). IOS have been identified as a key requirement for effective operation of IO relationships (Brue et al.,

\footnotetext{
${ }^{1}$ This article is an expanded and updated version of a conference paper "Inter-organizational Information Systems and Interaction in Public vs. Private Sector - Comparing two Cases”, in: Wimmer, M.A., Chappelet, J-L., Janssen, M., Scholl, H. (Eds.): EGOV 2010, LNCS 6228, IFIP, Springer, pp. 38-49.
} 
2002; Daniel and White, 2005) and have several impacts on governance, e.g., on a market level and an organizational level (Robey et al., 2008). IOS are therefore important to study when analyzing and developing IO interaction. IO aspects have been focused in general organization theory regardless of sector, where interaction in dyads and networks are vital objects for research (cf. Håkansson and Snehota (1989), who stated that no business is an island). This statement was later used in order to characterize government agencies in a network setting - "no government is an island" (Persson et al., 2006, p. 1420). If one turns to the private sector, business to business (B2B) interaction (e.g., Axelsson et al., 2002) is an area of increasing interest when discussing for example electronic commerce.

IO relations are also central when analyzing and developing government to government (G2G) interaction in order to achieve, e.g., useful one-stop government arrangements (Gouscos et al., 2007; Tambouris and Wimmer, 2004), in order to fulfill citizens' needs of integrated and responsive services and effective public organizations in general (Hazlett and Hill, 2003; Irani et al., 2007; Karunasena et al., 2011). E-government is considered to contain the next wave of IT solutions when private sector solutions (such as B2B and B2C applications) become more mature (Eyob, 2004; Irani et al., 2008).

IO interaction is the main theme addressed in this article. A comparative study of two cases will be presented based on the following research question: In what ways is private and public IO interaction similar and how does it differ depending on the sector context? The understanding of similarities and differences is useful as a point of departure when learning between private and public sector should take place. The need of comparative studies of e-business and e-government is put forth by Scholl (2006); Barzilai-Nahon and Scholl (2007; 2010), who argue that such comparative efforts are necessary but still rare. This article is a response to the shortage of research focusing comparative (inter sector) studies. The empirical part of this article contains a comparative study of two cases from the private and the public sector. The private sector is represented by a B2B relation between a carpentry and a sawmill - both small and medium size companies (SMEs) located in Sweden. The public sector is represented by a G2G relation between two agencies, one organization is Sweden's County Administrations (SCoA) and the other one is the Swedish Road Administration (SRoA $\left.{ }^{2}\right)$.

When a new research field, like e-government, is entered or in a phase of rapid growth there is a clear tendency that "wheels are reinvented". Learning from the past and from the experiences of other development initiatives is, thus, essential for improving e-government research and practice (Heeks and Bailur, 2007; Irani et al., 2007). Researchers as well as practitioners in the field tend to identify "too many" unique characteristics or unique factors related to the studied phenomenon, without learning from history and previous studies. On the other hand, there is another more or less opposite tendency; to take things for granted and, not critically enough, import or export ideas, concepts and lines of thinking from one area, sector or field to another. The IS field, dealing with e-government and e-business, is no exception in this case. Therefore it is important to conduct comparative case studies of different sectors in order to understand possibilities and restrictions for knowledge transfer between sectors.

The purpose of the article is to explore and discuss differences and similarities between e-government and e-business focusing IO interaction and the use of IOS to interact. This is done in order to facilitate learning between the two fields. The analysis will be conducted based on the IO concepts originally originating from industrial markets (Håkansson and Snehota, 1989; 1995) but later used and refined in an IO agency context (below). Theoretical concepts that characterize an IO relationship (continuity, complexity, symmetry, and formality) and concepts that describe dimensions of such relationships (links, bonds, and ties) (described in Section Three) are used in order to help us describe and analyze interaction. Theoretical concepts characterizing IO relationships including relationship dimensions have been applied to the e-government field in order to discuss challenges in one-stop government (Axelsson and Melin, 2008). In that study the IO concepts from industrial markets were refined and structured into a conceptual framework of IO agency relationship dimensions (ibid.). The conceptual framework is therefore used in order to structure and inform the comparative case study analysis.

After this introduction, the article is organized in the following way: In Section Two the research design is described, followed by the introduction of the case studies. The theoretical background to IO interaction as well as a comparison of IO interaction in e-business and e-government, and IOS

${ }^{2}$ Since 2009 the SRoA is a part of the Swedish Transport Agency. 
definitions are then presented in section Three. The empirical findings from the two cases are analyzed and compared, using concepts from the introduced interaction approach, in Section Four. The article is concluded in Section Five, together with implications, limitations and statements about further research.

\section{Research Design and Case Study Introduction}

\subsection{Research Design}

The research design of this study is qualitative and interpretive (cf. Myers, 2009; Van de Ven, 2007; Walsham, 1995; 2006). The fieldwork (case studies) has been conducted close to the cases and the involved practitioners. Based on this the researchers' had good access to interviewees, written sources and meetings, etc. The interviews had a semi-structured and semi-standardized design (based on an interview guide [see questions exemplified in the appendix] with pre-defined open questions and open ended questions and themes [Patton, 1980]) and were audio recorded. The interviewees have been selected in order to reach a broad view of apprehensions. Open questions about how they understand the notion of, e.g., IO interaction, IOS, communication, etc. were asked. The approach with multiple data sources and data collection methods also supports triangulation (Denzin and Lincoln, 1994; Miles and Huberman, 1994) of data and methods. Triangulation is performed in order to generate rich (multi-faceted) and valid data regarding e.g. relationship characteristics, administrative links, overall interaction IOS use and actors' bonds.

The empirical data has been analyzed in a qualitative, interpretive way, using theory as an analysis lens; i.e., central IO concepts from industrial markets (Håkansson and Snehota, 1989; 1995). This is in line with a strategy to use theory as a "part of an iterative process of data collection and analysis" (Walsham, 1995, p. 76). The central concepts used are summarized here and further elaborated on in Section 3.1.

Table 1 Relationship and interaction analysis - the analytic lens (concepts from: Håkansson and Snehota, 1989; 1995)

\begin{tabular}{|l|l|}
\hline Relationship Dimensions & Relationship Categories \\
\hline Overall Relationship Characteristics & Continuity \\
& \\
\cline { 2 - 2 } & Complexity \\
\cline { 2 - 2 } & Symmetry \\
\cline { 2 - 2 } & Level of Formality \\
\hline Links & Technical \\
\cline { 2 - 2 } & Administrative \\
\hline Activity & Commercial \\
\hline Bonds & Actor \\
\hline Ties & Economic \\
\cline { 2 - 2 } & Legal \\
\hline
\end{tabular}

Besides using the concepts as a part of the analysis (in Section 4.1 to 4.4 and in Table 2), the researchers tried to be open minded, investigating aspects and discoveries outside and beyond the theoretical concepts applied and to criticize the theoretical lens applied. The cases included in this article represent organizations from the public and the private sectors that have performed extensive work with IO dimensions (for example IO interaction and IOS). This makes them interesting to analyze and to compare. The cases have, of course, differences in terms of size, complexity, sector, management, type of IT systems, etc. and should not be interpreted as representing a statistical sample. Variation is instead regarded as an asset and the ambition has been to maximize the variation in order to achieve heterogeneous cases to analyze. When doing this there are of course limitations involved concerning the comparative analysis; all aspects of the cases are not possible or even interesting to compare. 


\subsection{Case Study Introduction}

\section{The E-government (G2G) Case Study}

The E-government (G2G) case study is focused on driving license issues. The IO interaction between two government agencies (CoA and SRoA) was studied during the issuing of provisional driving licenses. The overall process and background to this case is that everyone in Sweden who want to get a driving license, first have to apply for a provisional driving license from the regional CoA. The provisional driving license is approved if the applicant is judged by the regional CoA to be able to drive a vehicle in a safe way. The permit application was, until an e-service was implemented, a paper form that was filled in, signed and sent by mail to the regional agency. The application had to be complemented with a health declaration, a certificate of good eyesight, and maybe also an application that, e.g., a parent will be allowed to act as a private instructor. These documents were received and reviewed by a case officer at the agency. The case officer also checked if the applicant had been punished for any crimes. This information was registered in a database, operated by the police, which the case officer had access to through an IOS. When the provisional driving license had been granted, the CoA reported this to SRoA through this IOS. When the applicant has completed a driving test and a theoretical test successfully, she/he receives a driving license from the SRoA.

The development project that aimed at developing an e-service for handling the provisional driving license applications was studied. The e-service was intended to make an automated decision in "green cases" (i.e., cases that do not call for extensive handling) and support case officers handling such cases. By achieving this, the agency will in the long run try to save and reallocate resources from handling "green cases" to more complex errands. An e-service like this also provided an opportunity to standardize the application handling across the nation's 21 county administration boards.

\section{The E-government (G2G) Case Study Research Design}

The empirical data generated in this case has mainly been generated through semi-structured interviews (described above) with significant actors within the development project. In the beginning of the development project six persons involved in the project were interviewed. The interviewees had the following roles: an IT strategist, a development project manager, a system manager, an internal investigator, a case officer, and an IT development manager. Then seven persons were interviewed when evaluating progress and results in the end of the development project. Five of these interviewees were within the public sector; four of them were case officers and one of them was a local project manager at a CoA. Two interviewees were external consultants who worked for the public sector related to the studied e-government initiative. One of the consultants was a project manager supporter and the other person was an e-government development manager.

\section{The e-business (B2B) Case Study}

The e-business/business-to-business (B2B) case focuses the relation between two private owned firms in the wood industry; a sawmill and a carpentry. The studied sawmill is a family-owned company, established in the early 1900s. The business employs approximately 30 people. The sawmill exists in a volatile and competitive market, where raw materials are scarce and prices increasing. Securing the supply of raw material or logs is in focus. The carpentry manufactures a central component for houses; the stairs. The first product was manufactured already in the 1930s and since then production has continued in various forms of organization. 30 people are employed in the organization today including five administrators and the two joint owners. Since a couple of years, the firm enjoys very good profitability. The carpentry's business concept has remained the same since the beginning. The firm manufactures their product piece by piece, each product being unique.

Several development initiatives were studied within and between the two firms aiming at developing the business relation, the interaction and coordination as well as the use of IS in order to develop the interaction further. 


\section{The e-business (B2B) Case Study Research Design}

The two studied firms are a part of an industrial network that the authors have studied in a longitudinal multiple case study. The most significant unit of analysis was the firms and their business relations. Altogether 21 people in different positions were interviewed in the two focused firms, generating empirical data that is used in this study. Roles covered are, e.g., owners, managing directors, administrators, controllers, production managers, and mechanics/carpenters. Besides the empirical interview data documents (e.g., firms' business strategies) and artifacts (e.g., products, production layouts, logistic, and IS/IOS) were studied. Observations as empirical means for rich data were also conducted.

\section{Theoretical Background}

This section of the article presents theoretical core concepts from the so called Uppsala School - "the industrial/business network approach” (IMP - International/Industrial Marketing and Purchasing approach) and notions of how IO interaction can be compared in e-business and e-government settings.

\subsection{The Business Network Approach}

The industrial/business network approach (The IMP Approach), called the Uppsala School (e.g., Håkansson, 1982; Axelsson and Easton, 1992; Håkansson and Snehota, 1995), is a mature line of thinking (e.g. Axelsson, 2010) that supports the understanding of interaction in business networks. Today the approach is also used for understanding and analyzing marketing, distribution, purchasing, technological development and management from an interactive perspective, in B2B and B2C contexts, policy, and science-technology-business issues (ibid.). Interaction is an aspect of reciprocal action or interplay; it is not the case of just one organization acting and the other organization reacting. This way of understanding interaction takes a point of departure that it is a process that occurs between actors over time. The interaction process derives its particular content from the involved actors, but emerges in a way that is not fully controlled by either of them. Therefore interaction changes over time due to changes of the actors themselves, contributing to change and receiving change from others. These are important standpoints in the network approach.

If one elaborates more on the concept of interaction between organizations several characteristics of relationships can be identified; (1) continuity (2); complexity; (3) symmetry and (4) informality (Håkansson and Snehota, 1995).

1. Continuity refers to the relative stability that tends to characterize supplier and customer relationships.

2. The complexity in a relationship can among other things comprise the number, type and contact channels for those from each organization who are involved in relations between customer and supplier. Also, contacts can vary from level to level between organizations.

3. It is typical for relations in industrial networks for customers and suppliers to be symmetrical in terms of resources and initiatives on each side. In those cases where asymmetry does occur, the customer tends to be bigger than the supplier is.

4. The relationships often demonstrate a low level of formality. Even though contracts exist, they are seldom referred to, as it is often pointed out that contracts are an ineffective way of dealing with uncertainty, conflict or crises in relationships which are going to survive for some time. (ibid.)

Another important aspect to study, when analyzing interaction between organizations, is different dimensions of relations, such as links, bonds and ties (Axelsson and Easton, 1992; Håkansson and Snehota, 1995). The link dimension refers to the connections that exist in the activities between organizations, so-called activity links. An activity is defined as: "a sequence of acts directed towards a purpose" (Håkansson and Snehota, 1995, p. 52). Activities can be of various types, for example technical, administrative or commercial. The links between activities reflect the need for co-ordination which affects how and when various activities are carried out. Matching one actor's resources with 
others' and dividing out the tasks are examples of an aim towards purchasing and marketing functions within an organization. This, in turn, has consequences for both the costs for carrying out the activities and their effectiveness (Håkansson and Snehota, 1995). The links between activities make up a certain structure within the respect of organization at the same time as it also creates certain patterns in the network. Bonds between the actors in a network can be of various types, for example technical, social, time-based, knowledge-based, administrative, economic or legal (Håkansson and Snehota, 1995). Bonds arise in relationships as two related actors mutually acquire meaning in their reciprocal acts and interpretation (Håkansson and Snehota, 1995, p. 197). Bonds can have various aims, an example being to achieve co-ordination as a means of saving resources. To gain access to suitable co-operators and maintain a certain position in the network are other examples of the importance of handling bonds. "Actors act and develop bonds; at the same time they are a product of their bonds" (Håkansson and Snehota, 1995, p. 201).

An IO relationship affects the way in which the organizations use their personnel, equipment, knowhow, and financial resources, only to mention a few. A relationship between two organizations can comprise pooled resources of these kinds, so-called resource ties. The relationships between organizations are not just a way of assuring access to resources, they are also a way of getting various types of resources to meet, confront and combine (Håkansson and Snehota, 1995), and to develop, create or refine.

It is possible to identify several motives for applying these theoretical concepts when analyzing and comparing the two cases. The B2B case is obviously an illustration and an example of an industrial network. The G2G case does also possess characteristics of IO interaction. The Swedish model for public administration implies that cooperation between agencies in Sweden relies on similar foundations as cooperation between private organizations, i.e., there is a large amount of semiautonomous agencies (Government Offices of Sweden, 2008) that have to find ways to cooperate and coordinate their joint development projects. Thus, one can argue that IO relationships between agencies have some characteristics in common with business relationships in other networks. Another reason is that cooperation in the public sector sometimes involves financial exchange, which makes cooperation similar to cooperation in a business network (cf. Axelsson and Melin, 2008). This implies that the network approach would be able to extend, refine to and apply in an analysis of interaction between actors within the public sector.

\subsection{Comparing IO Interaction in E-business and E-government}

Historically, IS research has been argued to be less successful in developing cumulative research (Benbasat and Zmud, 1999). For most phenomena being studied, a new theoretical frame has been put forward instead of careful analysis of already existing frames. Strong theoretical frames with real value are, thus, rare (ibid.). This is something Heeks and Bailur (2007) also emphasize as weak or confused positivism in e-government research dominated by over-optimistic and a-theoretical work, which do not add much practical guidance to e-government. The ambition is to adopt core concepts from the mature IMP approach on the B2B and G2G cases in this article. It is, thus, an attempt to apply and analyze an already existing theoretical frame instead of inventing a new one.

There are few research studies focusing on comparison between e-business and e-government issues (Scholl, 2006). Instead, these two fields are either - using a dichotomy - seen as:

1. Closely related (if focusing on IT aspects) or

2. Totally different (if focusing on funding mechanisms, some governance aspects and other organizational drivers).

Both these standpoints might be harmful in theory and in practice since they imply that knowledge either can be transferred between the fields in an uncritical way or that no lessons can be learned based on comparisons. In this article it is assumed that an increased understanding of how B2B and G2G interactions are alike and different can help improving both fields. This assumption is confirmed by Barzilai-Nahon and Scholl (2007) who argue that both the private and the public sectors would benefit from a better understanding of similarities and differences regarding e-business and e-government. They present a study that identifies several areas of similarities between e-business and e-government; i.e., process improvements, back-end integration, cost savings, information sharing, vertical and 
organizational e-systems integration, increased responsiveness and service quality, standardization efforts, and the criticality of senior leadership support. They distinguish some areas of differences as well; i.e., the drivers and motivations for e-business and e-government, stakeholder expectations, and resource availability (ibid.). All in all, Barzilai-Nahon's and Scholl's (2007) findings show that there seem to be many aspects where it is possible to identify similarities, but there is also need to understand the differences in order to avoid exaggerated knowledge reuse. In a longitudinal study reported in 2010 on the same theme Barzilai-Nahon and Scholl also found the trajectories of ecommerce and e-government quite distinct such that one can hardly serve as a role model for the other. This is in line with the basic assumptions in the present research. In the paper from 2010 they also argue for the need to use the high potential for cross-pollination between the two fields. Their studies do, however, not focus on IO interaction in any detail, which implies that the study fills a gap in this respect. Several e-government scholars emphasize that the e-government field has disregarded IO aspects even though these seem to be a major cause for many problems (Punia and Saxena, 2004; Tranmüller and Wimmer, 2003). This supports the objective in this article to explore how knowledge can be transferred (carefully and consciously) between B2B and G2G fields considering contextual conditions in governance, commission, etc. Schedler and Summermatter (2004) claim that there are three central statements that constitute the key to a comprehensive understanding of e-government: 1 ) e-government uses IT, especially the Internet, 2) e-government deals with organizational aspects of public administration; and 3) e-government considers the interaction of public administration with its environment (e.g. customers, suppliers, citizens, politicians). This is other arguments supporting the need for research covering the use of IOS and IO interaction.

\subsection{Inter-organizational Information Systems}

IOS are information systems that in some sense cross organizational boundaries and are shared by two or more organizations (Robey et al., 2008); i.e., IT systems that support B2B, G2B or G2G interaction. IOS are used to support IO interaction and, e.g., coordination between organizations. There are several studies covering IOS development and use. Early and seminal studies are performed by different scholars (Holland, 1995; Kumar and van Dissel, 1996; Webster, 1995). These and other early studies have been used as point of departure for many following studies of IOS. Kumar's and van Dissel's theory (1996) has, e.g., been expanded by Fahy et al. (2007) updating current conceptualizations of IOS in the context of emerging global environments. Roles of the organizations cooperating via an IOS are the basis for another framework proposed by Hong (2002). There are also studies of theoretical foundations of IOS (e.g., Robey et al., 2008).

IOS exist in a dialectic relation with business processes and the structure of organization or relationship between organizations. A higher level of structure and formalization can be a result when using IOS in IO interaction (Kumar and van Dissel, 1996). Formalization exists, e.g., when there are tightly coupled IOS that require extensive relationship specific investments (Goethals et al., 2005). Tightly coupled IOS are associated with reduced flexibility (Goodhue et al., 1992). EDI was an early example of this. Internet and extranet solutions on the other hand have made data interchange, interaction and communication easier to perform cross organizations. Enterprise systems are shifting from internal to external focus and IO operations are increasingly important to handle (Daniel and White, 2005). However, such solutions will require integration with internal IS in order to work efficiently (ibid.; Yang and Papazoglou, 2000).

\section{Analysis}

In the sections, below, the overall relationship characteristics will be analyzed in the cases from the two sectors using core concepts from the IMP approach (Axelsson and Easton, 1992; Håkansson, 1982; Håkansson and Snehota, 1989) presented earlier in the article. First the overall relationship characteristics (continuity, complexity, symmetry and level of formality) are analyzed in Section 4.1 followed by the relationship dimensions (links, bonds and ties) in Sections 4.2-4.4. The analysis is structured according to a conceptual framework of IO agency relationship dimensions (Axelsson and Melin, 2008) and summarized in Table 2. 


\subsection{Relationship Characteristics}

\section{B2B Case}

The business relation between the sawmill and the carpentry firm is characterized by its stability and long term (established in the beginning of the 1980ies) continuity. The sawmill experiences a certain responsibility as a major supplier (in monetary terms, not in production volume) of wood to the carpentry in order to guarantee its production and its need for raw material with certain qualities. On the other hand the carpentry firm is a major, and very important, demanding customer for the sawmill. The stable and long term business relation is also dynamic in terms of the common intention to improve and innovate in processes and products. Several joint efforts taken (described below) strengthen the business relation and make it more efficient, e.g., in terms of comparative advantage.

There is a low level of complexity in the relation. The communication process and the overall exchange process are uncomplicated and straight forward. A small number of actors have contact with each other between the organizations; contacts are based on mutual trust and mutual adjustment and contain personal bonds (described below).

The carpentry has a clear initiative in the relationship and the relation is in that sense asymmetrical. The carpentry firm is a demanding customer, suggesting and implementing improvements. The sawmill has a strategy to adjust to (changing) customer demands and initiatives. The level of formality in the business relation is low. Even though written frame contracts exist, they are seldom referred to. Mutual understanding and agreement are more present. There are variations in for example the corporate culture and history, but the companies have a lot in common; such as the regional relation, the SME character, and activity in the wood industry.

\section{G2G Case}

The actors within the G2G case and the focused relation are stable and mature, which seems to be less challenging than the opposite. The continuity in the relationship and the division of labor is regulated in law by the Swedish government.

The relationship consists of many agency actors involved in interaction (e.g. at different organizational levels, and in different handling processes) and the studied development project. This makes the complexity in the relation rather high. Handling many citizens' applications generates a high volume of errands and a complex process to coordination. There are diverse conceptions about the components of the complexity among different interviewed actors; e.g. regarding what complexity is (a bulk volume of errands to handle or complex communication patterns, complex estimation within case handling), but the overall complexity is regarded as high.

Goal conflicts between several overarching roles, responsibilities and missions exist between the two agencies. The SRoA is the dominating part in the relationship in terms of resources and different kinds of knowledge (concerning, e.g., e-services, project management skills, approaches and methods, IT resources, IT know-how). SCoA is a more diversified and divided agency that works with many different cross-sectoral issues, which is also rooted in its organizational distributed structure. The G2G relation is considered as asymmetrical.

A high level of formality concerning the division of labor exists between the parties regulated by the government as mentioned above. This certainly has an influence on the relationship forming a formal point of departure and a frame to act within. However, different apprehensions about division of labor and responsibility occur between the two agencies. Variation in, e.g., project management approaches and government organization cultures also exists. For example, the SRoA has a tradition in leading major building and infrastructure projects; this permeates the organization and the collective norms. A rather male construction and engineering culture is present. The SCoA on the other hand has an operation that spans over several areas more directed towards traditional administration and public coordination. On a general level they work for a development where the environment, economic growth and good living conditions go hand in hand and they are responsible for implementing decisions from parliament and the government in particular counties. Areas of expertise span the social issues of diverse kinds, from rural development and biodiversity aspects of integration to protection of cultural sites. 


\subsection{Links}

\section{B2B Case}

The links between activities reflect the need for co-ordination which affects how and when various activities are carried out. Matching one actor's resources with others' and dividing out the tasks are examples of an aim towards purchasing and marketing functions within an organization, as stated above. This, in turn, has consequences for both the costs for carrying out the activities and their effectiveness (Håkansson and Snehota, 1995).

Several links between the two companies in the B2B relation are identified. A distinct pattern of matching resources with others' and dividing out the tasks are identified in the business relation. This can be exemplified by an exclusive view in the sawmill stock IT system created so that they can expose the products that are unique for the carpentry; i.e. a technical link. This is an example of a "non-advanced" (technically) IOS, but very efficient in terms of organizational benefits. These products exposed in the IOS are also put into a special destined physical space in the factory building in order to be easy to handle and to transport efficiently to this particular customer.

Administrative links are represented by the rather simple - but efficient - individually and mutually agreed patterns of communication and cooperation. The patterns of communication and cooperation are of an emergent character. There are some disintegrated processes within the two firms (e.g., between marketing and production) boundaries, but the integration between the two firms are higher (institutionalized communication patterns within administrative processes).

Sequential interdependencies between activities (activity links) in relation between the two companies are present (e.g., in order and delivery processes). The sawmill, to a large extent, adapts the activities to this customer's needs. Information and goods are exchanged in the business relation.

There are several commercial links in the studied B2B relation. The sawmill has invested in a dedicated production equipment, stockroom, and IT, in order to satisfy demands from this important and demanding customer. The carpentry has invested in competence transfer and development efforts directed towards their major supplier.

\section{G2G Case}

The major technical link in the G2G case is the IOS (the national Road Traffic Register) provided by the SRoA to the 21 CoAs. The latter organizations use the IOS as an important tool for handling provisional driving license applications. Data from the traffic register is used in the new e-service developed for handling applications in the studied project; i.e. systems integration exists.

An important administrative link in the focused relation can be characterized as a disintegrated process with many contacts and delivery sub-processes between the two agencies. The agencies have responsibilities for different phases in the process of handling provisional driving licenses. For example, the CoAs handle the applications for provisional driving licenses (as described above), the SRoA manages the theoretical and practical (driving) tests and issues the driving license.

Information and service is exchanged in the studied relation. The SCoA has to adapt to the IT system supplied by the SRoA (discussed above); but has some possibilities to express requirements on design of the IT system and the use of the system in the role of being an important external user.

\subsection{Bonds}

\section{B2B Case}

The two firms in the B2B case are typical SMEs with flat, non-hierarchical organizational structures, with few organizational levels. In this case, particularly the carpentry firm can be characterized as an effective-entrepreneurial firm with an organic structure that enhances communication and minimizes bureaucratic barriers to innovation (cf. Covin and Slevin, 1988; Chaston, 1997; Mintzberg, 1979). Actor bonds within and between the two firms rely mainly on a personal (social) dimension, built up 
from the long-term business relationship and a common, genuine, interest in organizational development, entrepreneurship and pride connected to the material (wood) as such.

The sawmill depends a lot on the demand from the carpentry (in production volume and economic terms) - this creates a clear economic bond between the two firms. The ROI and the economic result on the bottom line is higher at the carpentry than at the sawmill; which also influences the symmetry in the business relation.

Written frame contracts occur (creating legal bond between the firms), but are seldom referred to. Legal bonds are implicit in the relation and in the interaction between actors from the two firms. Bonds are instead created based on mutual trust and a long-term business relation.

\section{G2G Case}

A gap between participants in working groups on different hierarchical levels (so called action groups; one at the operative level and one at the strategic level) exists in the studied relation within and between agencies (actor bonds). It is also identified that history influences opinions about the present and future division of labor between agencies which is often criticized and discussed. Some respondents call attention to the disparate and disintegrated processes of driving licenses arguing that a more integrated process should be more efficiently handled by one or at least fever actors.

When the economic bonds are investigated, complex principles for compensation related to the performance of activities exist between the two agencies are identified. Some tasks are very resource demanding (e.g., handling complex "red" errands that result in a rejected application) but still uncompensated.

The agencies have several external assignments and both superior and inferior roles towards each other (legal bonds). The SCoA has an explicit mission from the government to develop e-services (introduced above). The SRoA, on the other hand, has the overall responsibility for national road traffic issues sanctioned by the government. This fact also influences the bonds between the parties and the asymmetry (above) in the relation.

\subsection{Ties}

\section{B2B Case}

A number of pooled resources are jointly connected to the product (the customized wood material) and the production (equipment, structuring and organization, know-how) constituting resource ties between the two firms. Know-how is also transferred from the carpentry to the sawmill in order to increase the level of refinement in the product and in the infrastructure supporting the production.

\section{G2G Case}

The studied parties pool resources (personnel and know-how) in order to develop e-services in a joint development project and are therefore tied together - temporarily for the development process and possibly also over time. At the same time there is an asymmetry in incentives for the joint project influences and the amount of resources spent on the project, e.g., due to the fact that the SRoA has an in-house IT development staff (with technical skills, project management skills, and purchasing competence) and the SCoA lacks this in-house competence. Knowledge is both a resource used in the development project and an outcome from the project; i.e., competence development on both individual and organizational levels.

\subsection{Relationship and Interaction Analysis - A Summary}

Table 2. Relationship and interaction analysis - a summary of the comparative study of the B2B and G2G cases

\begin{tabular}{|l|l|l|l}
\hline Relationship & Relationship & Business (B2B) Case & E-government (G2G) Case
\end{tabular}

Dimensions $\quad$ Categories 


\begin{tabular}{|c|c|c|c|}
\hline \multirow{4}{*}{$\begin{array}{l}\text { Overall } \\
\text { Relationship } \\
\text { Characteristics }\end{array}$} & Continuity & Stable and mature (long term) relationship. & $\begin{array}{l}\text { Stable and mature relationship (the relationship } \\
\text { and the division of labor is regulated in law). }\end{array}$ \\
\hline & Complexity & $\begin{array}{l}\text { Low level of complexity. The communication } \\
\text { and the exchange process are uncomplicated. } \\
\text { A small number of actors are involved. }\end{array}$ & $\begin{array}{l}\text { High level of complexity (many agency actors and } \\
\text { many citizens' applications). Diverse conceptions } \\
\text { about the components of the complexity. }\end{array}$ \\
\hline & Symmetry & $\begin{array}{l}\text { Asymmetrical. The carpentry has a clear } \\
\text { initiative in the relationship. The sawmill adjusts } \\
\text { to customer demands and initiatives. }\end{array}$ & $\begin{array}{l}\text { Asymmetrical. The SRoA is the dominating part in } \\
\text { the relationship. SCOA is more diversified. }\end{array}$ \\
\hline & $\begin{array}{l}\text { Level of } \\
\text { Formality }\end{array}$ & $\begin{array}{l}\text { Low level of formality. There are variations in } \\
\text { the corporate culture, history, etc., but the } \\
\text { companies also have a lot in common. }\end{array}$ & $\begin{array}{l}\text { High level of formality concerning the division of } \\
\text { labor exists between the parties. }\end{array}$ \\
\hline \multirow[t]{4}{*}{ Links } & Technical & A technically "non-advanced", but efficient, IOS. & $\begin{array}{l}\text { The SRoA supplies the IOS that the } 21 \text { CoAs use } \\
\text { as an important tool for handling the applications. } \\
\text { Information systems integration exists. }\end{array}$ \\
\hline & Administrative & $\begin{array}{l}\text { Rather simple and individual patterns of } \\
\text { communication and cooperation. Integrated } \\
\text { processes between the firms, but disintegrated } \\
\text { processes within the firms. }\end{array}$ & $\begin{array}{l}\text { Complicated patterns of communication and } \\
\text { cooperation. Disintegrated process between } \\
\text { agencies. The agencies have responsibilities for } \\
\text { different phases in the common process. }\end{array}$ \\
\hline & Activity & $\begin{array}{l}\text { Sequential interdependencies between } \\
\text { activities in the two firms. } \\
\text { Information and goods exchange. }\end{array}$ & $\begin{array}{l}\text { Dependencies and activity links in terms of the } \\
\text { fact that the SCOA has to adapt to the IT system } \\
\text { supplied by the SRoA. } \\
\text { Information and service exchange. }\end{array}$ \\
\hline & Commercial & $\begin{array}{l}\text { The sawmill has invested in a customer } \\
\text { dedicated production equipment. }\end{array}$ & Not applicable in this case. \\
\hline \multirow[t]{3}{*}{ Bonds } & Actor & $\begin{array}{l}\text { Flat, non-hierarchical organizations, with few } \\
\text { organizational levels. Actor bonds rely on a } \\
\text { personal (social) dimension between the firms, } \\
\text { built up from the long-term relationship. }\end{array}$ & $\begin{array}{l}\text { A gap between participants in working groups on } \\
\text { different hierarchical levels within and between } \\
\text { agencies. History influences opinions about } \\
\text { present and future division of labor between } \\
\text { agencies. Implicit actor bonds. }\end{array}$ \\
\hline & Economic & $\begin{array}{l}\text { The sawmill depends a lot on the demand from } \\
\text { the carpentry. The ROI is higher at the } \\
\text { carpentry than at the sawmill. }\end{array}$ & $\begin{array}{l}\text { Complex principles for compensation related to } \\
\text { the performance of activities; some tasks are } \\
\text { resource demanding but uncompensated. }\end{array}$ \\
\hline & Legal & $\begin{array}{l}\text { Written frame contracts occur, but are seldom } \\
\text { referred to. Legal bonds are implicit in the } \\
\text { relation and in the interaction between actors. } \\
\text { Bonds are based on long-term mutual trust. }\end{array}$ & $\begin{array}{l}\text { The agencies have several external assignments } \\
\text { and both superior and inferior roles towards each } \\
\text { other legally regulated. }\end{array}$ \\
\hline Ties & Resource & $\begin{array}{l}\text { A number of pooled resources are jointly } \\
\text { connected to the product and the production } \\
\text { process. Know-how is also transferred from the } \\
\text { carpentry to the sawmill in order to increase the } \\
\text { level of refinement in the product. }\end{array}$ & $\begin{array}{l}\text { Pooling of resources (personnel and know-how) } \\
\text { in order to develop e-services in a joint } \\
\text { development project. Knowledge is both a } \\
\text { resource used in the project and an outcome. }\end{array}$ \\
\hline
\end{tabular}

\section{Conclusions, Limitations and Further Research}

In the introduction of this article it is asked in what ways private and public IO interaction is similar and how it differs. The ambition has been to understand similarities and differences in order to explore when and how the e-business and e-government fields can learn from each other, carefully and consciously, regarding IO interaction. The contributions of the present study are presented as: (1) identified differences and similarities in the studied cases, (2) mutual learning between the fields, (3) further understanding of interaction and IOS empirically and theoretically, and as (4) suggested, explorative, refinements of the conceptual framework used for analytical comparisons of B2B and G2G interaction (elaborated on above). This section ends with a summary of the conclusions, implications and limitations of the present study and suggested themes for further research.

\subsection{Private vs. Public IO Interactions - Differences}

The conclusions, based on applying the IMP approach (Axelsson, 2010; Axelsson and Easton, 1992; Håkansson, 1982; Håkansson and Snehota, 1989, 1995), show that there are differences between the interaction in the studied cases from the two sectors. If one takes a closer look at the overall 
relationship characteristics there are differences, at the empirical case level, but the theoretical categories support the analysis in an appropriate and informative way. Important factors contextually framing the interaction and the relations are, e.g., present in the G2G case. In this case the government governs and regulates the present processes, actors, and division of labor. In the B2B case we also have laws and regulations, but on another level (e.g., concerning accounting and different types of permits.). From the empirical data differences in the level of formality, asymmetry, the use of technical systems (e.g., the use of an IOS), organizational structure (actor bonds), economic bonds and administrative links (summarized in Table 2) have also been identified. Legal and actor bonds (content) also differ between the cases.

Barzilai-Nahon and Scholl (2007) distinguish some areas of differences between B2B and G2G sectors; i.e., the drivers and motivations for e-business and e-government, stakeholder expectations, and resource availability (cf. Flak and Rose, 2005). All in all the findings (Barzilai-Nahon and Scholl, 2007) show that even though there are many aspects where it is possible to identify similarities, there is also a need to understand the differences in order to avoid improper (non context sensitive) knowledge reuse or use of knowledge as a part of adopting uncritical management fashion or translation of ideas (cf. Morris and Lancaster, 2006).

\subsection{Private vs. Public IO Interactions - Similarities}

The conclusions based on using core concepts from the IMP approach (Axelsson and Easton, 1992; Håkansson, 1982; Håkansson and Snehota, 1989, 1995) show that there are similarities between the cases from the two sectors both on an empirical level and on an analytical level (the used categories). For example, both relations are stable and mature (continuity), have disintegrated processes (administrative link), sequential interdependencies (activity link) and pooled resources (resource link) (see Table 2). Earlier in this article it was assumed that increased understanding of how B2B and G2G interaction are alike and different can help improving both fields. One can argue that the present study has shown that this is the case, in line with Barzilai-Nahon and Scholl (2007; 2010). However, there is a need to separate the analytical level from the empirical level. The present study shows that it is possible to use the same set of categories when analyzing B2B and G2G relations and the present interaction. The result of using the same set of categories, however, can differ due to what type of organizations (firms or government agencies) that are analyzed, based on contextual factors. It can be concluded that the present study also shows that there are several areas of similarities between ebusiness and e-government, as identified above. There is a reported need to continuously improve intra- and IO processes, back-end vs. front-end integration, cost savings (efficiency), vast communication and information sharing, the need for IT integration, increased responsiveness and service quality, standardization efforts, and the criticality of senior leadership support (Barzilai-Nahon and Scholl, 2007). The last aspect, however, more implicit in the rather non-hierarchical SME's in the present empirical data. The reported study (ibid.) does, however, not focus on IO interaction, which implies that the present study adds value.

\subsection{Mutual Learning in B2B (e-business) and G2G (egovernment)}

After having analyzed the interaction in the B2B and G2G cases using the IMP approach, it can be argued that the use of the relationship characteristics and the relationship dimensions are useful when structuring, describing and analyzing interactions - regardless of focused sector. However, there are aspects that can be made more explicit. There are also indications that a "careful" mutual learning in the two fields can occur when taking their differences and similarities into account (cf. Barzilai-Nahon and Scholl, 2007; 2010). Based on the comparative analysis it is also suggested that the conceptual framework of IO agency relationship dimensions (Axelsson and Melin, 2008) can be further developed. Organizational size and culture are aspects that can be made more explicit as well as the aim to create value for an end-customer (end-client or citizen). Organizational culture is a characteristic that can be made more explicit for two studied organizations and their joint relation, as the existing organizational cultures influence the IO relation. Differences in organizational culture in two interacting organizations are of particular interest to focus as such differences probably can explain certain characteristics of the relationship. The organizational culture is also related to the categories "level of formality" and "actor bonds" in the IMP approach (Axelsson and Easton, 1992; Håkansson, 1982; Håkansson and Snehota, 1989). 
In the present research there is also identified a need to be more explicit regarding the exchange object (services, products and information). Different types of objects have effects on how communication and interaction will be performed. There will be certain constraints and possibilities influencing the interaction depending on present exchange characteristics. The relation will also be labeled in different ways depending on the object for exchange; the studied relationship can be a customer and supplier relationship or a patient and physician relationship, to mention two examples. If the interaction in focus is supported by an IOS as an example of a technical, administrative and activity link, these aspects are also important in order to create organizational and end-customer or client/citizen value. Such applications can be viewed as back-office systems, but has an effect on what joint value organizations can create. The last two characteristics are important to make explicit if organizations are developing different inter-organizational information systems or e-services. In order to compensate for the weak focus on IT (IOS) or e-services within the IMP approach, this is commented upon in the following section.

\subsection{IO Interaction and IOS}

In the B2B case, a "non-advanced" IOS was used; the sawmill has created a view in their stock IT system where customer unique products can be exposed (a technical link summarized in Table 2). This improves and simplifies the interaction between the two firms, without being expensive and resource demanding as an investment (Breu et al., 2002; Daniel and White, 2005). This type of IO application is tied to this particular key customer, using a remote login solution, but can, hypothetical, be used for several customers. It is not technological issues that limit the IOS; it is more a question of trust - trust in technology and trust in institutions (Belánger and Carter, 2008; Smith, 2011). Trust based on a stable and mature (long-term) relationship between the two parties. The IOS is tightly coupled, but it has required extensive relationship specific investments (cf. Goethals et al., 2005); at least not in direct IT investment terms - rather in mutual trust.

In the e-government case a development project that aimed at developing an e-service for handling the provisional driving license applications was studied. The e-service was intended to make an automated decision in "green cases". This system has IO parts (supporting IO interaction [C2G]) and is integrated with systems at several other government agencies in order to exchange data concerning, e.g., crime records and residential information. Links to the Road Traffic Register are important in the daily work handling applications for provisional driving licenses. The IOS improves and simplifies the interaction (even if it is mainly unidirectional) between the studied agencies (Breu et al., 2002; Daniel and White, 2005). The IOS is tightly coupled, and has required extensive relationship specific investments (cf. Breu et al., 2002). The dependency that the technical link represents will probably decrease flexibility (Goodhue et al., 1992).

\subsection{Suggested, explorative, Refinements of the Conceptual Framework for Understanding B2B and G2G Interaction}

Links, bonds and ties based on Axelsson and Easton (1992) and Håkansson and Snehota (1995) are possible to use when comparing interaction between organizations in the two sectors according to the analysis above. The difference in the use of the link category "commercial" between the two sectors made us aware of the need to discuss and analyze the "value" category as an alternative and a possible expansion of the IMP approach's concepts. The commercial link from the B2B case (summarized in Table 2) can, instead of being marked "Not applicable" in the G2G case, be changed to "Value". By proposing this change it is possible to be more explicit concerning the value for 1) the studied organizations and 2) the end-customer (end-client or citizen) that, e.g., a particular G2G constellation (cf. SRoA and SCoA working efficiently together in this case) mutually aims to achieve. This is also one example of how a category from the IMP approach can be made more abstract (analytical independent of a specific sector) and refined in order to fit analysis of organizations and their relations in both private and public sectors. One can also discuss which role the size of the studied organizations has had when comparing the empirical data. The size of the organizations has some effects on how they organize processes and hierarchy levels. But in the same time the size and structure of the private and public sectors are given by the market and the overall structure of the public sector on a national level. The relative size is implicitly present in the symmetry category for the specific relation based on the IMP approach (as summarized in Table 2), but can be made more analytically explicit for a unique organization related, e.g., to other actors in a market or on a governmental level. This is another example of a refinement needed. 


\subsection{Conclusions and Implications}

Based on the analysis and the results above it is possible to conclude that the development and use of information systems (IOS or e-services) permeate several links between organizations (e.g., technical, administrative and activity links) (Section 5.4). Analyzing links in a structured way is a fruitful approach in order to highlight IO relationship dimensions. The IOS embeds the IO interaction. This calls for the need also to study these aspects even further - empirically and theoretically. This study has, thus, pinpointed the need for further studies in this area. Linking back to the research questions addressed in this paper it can be concluded that:

- The findings in the present study show that there are several similarities concerning interaction in relations between organizations in the two sectors. There are also differences depending on the level of analysis (empirical level vs. analytical level) (Section 5.1 and 5.2).

- The study shows the need to be explicit regarding organizational value, end-customer or client/citizen value and the type of objects that are exchanged in the interaction.

- The study also shows clear benefits from using the IMP approach when structuring, describing and analyzing interactions (of the relationship characteristics and the relationship dimensions) - regardless of focused sector (Section 5.3).

It is also possible to consider the opportunity to "carefully" learn between the two sectors as promising; taking its differences and similarities into account (Section 5.3). This study, thus, contributes to the body of knowledge concerning IO interaction and IOS between organizations in research and practice.

The innovative part of this study is the use of concepts from the IMP approach (Axelsson and Easton, 1992; Håkansson and Snehota, 1995) in a comparative study covering G2G and B2B IO interaction. The implication and the contribution to interaction and network studies is the refinements outlined above (Section 5.5) based on an inter-sector, comparative, study. As stated above the IMP approach has its roots in an industrial setting. The major implication and contribution from this study to the egovernment field is to provide and illustrate a systematic, and theoretically grounded, way of analyzing IO interaction and the use of IOS. The empirical illustration as such, with the inter-sector comparative study, also has a value addressing similarities and differences and a potential learning between the two sectors. The need of comparative studies of e-business and e-government is put forth by Scholl (2006); Barzilai-Nahon and Scholl (2007; 2010), who argue that such comparative efforts are necessary but still rare. Presenting the results above the aims is to contribute to cumulative research in the IS and e-government area focusing IO interaction and IOS development and use. This is also a response to the criticism reported by Benbasat and Zmud (1999) in the IS area as well as by Heeks and Bailure (2007) in the e-government area, addressing the less success in cumulative research, the lack of theoretical frames or a-theoretical work.

\subsection{Limitations and Further Research}

Further research is needed in order to compare different types of organizations in the two sectors. Further research is also needed covering G2G and B2B relations in general. The sample of organizations, and the relations, can be enlarged and chosen based on differences in business type, industries, local government, state, size, and types of services. This would add further understanding of the possibilities to achieve mutual learning about IO interaction in B2B and G2G. Choosing the cases that are present and analyzed in this article is a limitation, as pointed out above, but the variation represented here is also an opportunity. Based on the comparative study, it is also identified that even if an organization is a part of a particular sector, the organizations in a certain sector are not homogeneous. The character of the organization can be made more explicit when analyzing its relations. This is another limitation of the present research. However, the comparison in this article indicates that the identified characteristics can be made more precise compared to the presented relationship characteristics and dimensions (links, bonds and ties) (Håkansson, 1982; Håkansson and Snehota, 1995) as well as the conceptual framework of IOS agency relationship dimensions (Axelsson and Melin, 2008). The identified characteristics concerns: organizational size, value and culture, the exchange object (services, products, information), service level, end-citizen/customer value, and the use of IT or e-services (IOS) as an example of an intertwined technical, administrative and activity links. These indications can be related to the existing body of knowledge and analyzed in more detail. However, this is out of the scope of this study and an issue for further research. 
Another interesting area for further research is how to deal with public-private partnerships (PPPs). Studying PPPs could further challenge the categories discussed above. In such cases, where private and public sectors meet, the kind of results that is reported in this piece of research appears to be valuable. To learn more about IO interaction between a private and a public organization would be beneficial for understanding both sectors. Trust is an important issue which is embedded in the IMP approach (Håkansson and Snehota, 1989, 1995), but can also be highlighted conducting studies focused on trust explicitly (cf. Bellamy and Taylor, 1998; Hardin, 1999; Smith, 2011) or as an embedded part of studying the management of for example e-government or service development as such (e.g. Angelopoulos et al., 2010; Melin and Axelsson, 2009).

\section{References}

Angelopoulos, S, Kitsios, F., Papadopoulos, T. (2010). New Service Development in e-government: Identifying Critical Success Factors, Journal of Transforming Government - People, Process and Policy, 4(1), 95-118.

Axelsson. B. (2010). Business Relationships and Networks: Reflections on the IMP tradition, IMP Journal, 4(1), 3-30.

Axelsson, B. and Easton, G. (1992, Eds.). Industrial Networks: A New View of Reality, Routledge, London.

Axelsson, K., Melin, U. (2008). An inter-organisational perspective on challenges in one-stop government, Int. Journal of Electronic Governance, 1(3), 296-314.

Axelsson K, Melin, U., Goldkuhl, G. (2002). Understanding B2B interaction - A model to accentuate inter-organisational systems design issues, In: Wrycza, S. (Ed., 2002): Proceedings of the $10^{\text {th }}$ European Conference on Information Systems, Gdansk, Poland, June 6-8, 2002, 541-550.

Barzilai-Nahon, K., Scholl, H.J. (2007). Similarities and Differences of E-Commerce and eGovernment: Insights from a Pilot Study, Proceedings of the $40^{\text {th }}$ Annual Hawaii Int. Conference on System Sciences (HICSS’07), 92-101.

Barzilai-Nahon, K., Scholl, H.J. (2010), Siblings of a Different Kind: E-Government and ECommerce, In: Wimmer MA, Chappelet J-L, Janssen M, Scholl HJ (Eds.), Proceedings of the $9^{\text {th }}$ IFIP WG 8.5 International Conference, EGOV 2010, Lausanne, Switzerland, 30 August - 2 September 2010, 25-37.

Bélanger, F. and Carter L. (2008). Trust and risk in e-government adoption, Journal of Strategic Information Systems, 17(2), 165-176.

Bellamy, C. and Taylor, J.A. (1998). Governing in the Information Age, Buckingham: Open University Press.

Benbasat, I., Zmud, R.W. (1999). Empirical Research in Information Systems: The Practice of Relevance, MIS Quarterly, 23(1), 3-16.

Breu, K., Hemingway, C., Strathern, M., Bridger, D. (2002). Workforce agility: the new employee strategy for the knowledge economy, Journal of Information Technology 17, 21-31.

Cavaye, A.L.M., Cragg, P.B. (1995). Factors Contributing to the Success of Customer Oriented Interorganizational Systems, Journal of Strategic Information Systems, 4(1), 13-30.

Chaston, I. (1997). Small firm performance: assessing the interaction between entrepreneurial style and organizational structure, European Journal of Marketing, 31(11/12), 814-831.

Covin, J.G., Slevin, D.P. (1988). The influence of organisational structure on the utility of an entrepreneurial top management style, Journal of Management Studies, 25(3), 217-237.

Daniel. E.M., White, A. (2005). The Future of Inter-organisational System Linkages: Findings of an Int. Delphi Study, European Journal of Information Systems, 14(2), 188-203.

Denzin, N.K., Lincoln, Y.S. (1994). Entering the Field of Qualitative Research. In: Denzin, N.K. and Lincoln, Y.S. (Eds.): Handbook of Qualitative Research, Sage.

Eyob, E. (2004). EGovernment: Breaking the Frontiers of Inefficiency in the Public Sector, Electronic Government, 1(1), 107-114. 
Fahy, M., Feller, J., Finnegan, P., Murphy, C. (2007). Complexity and Context: Emerging Forms of Collaborative Inter-Organizational Systems, Journal of Information Technology Theory and Application, 8(4), 1-12.

Flak, L.S., Rose, J. (2005). Stakeholder Governance: Adapting Stakeholder Theory to e-government, Communications of the AIS (16), 642-664.

Ford, D., Gadde, L-E, Håkansson, H., Snehota, I., Waluszewski, A. (2010). Analysing Business Interaction, IMP Journal, 4(1), 82-103.

Goethals, F, Vanderbulcke, J., Lemahieu, W., Snoeck, M., Cumps, B. (2005). Two basic types of business-to-business integration, Int. Journal of E-Business Research, 1(1), 1-15.

Goodhue, D.L., Wybo, M.D., Kirsch, L.J. (1992). The Impact of Data Integration on the Costs and Benefits of Information Systems, MIS Quarterly, 16(3), 293-311.

Gouscos, D., Kalikakis, M., Legal, M., Papadopoulou, S. (2007). A general model of performance and quality for one-stop e-government service offerings, Government Information Quarterly, 24(4), 860-885.

Government Offices of Sweden. (2008). eGovernment Action Plan, drafted by the eGroup and the State Secretary Group for eGovernment Coordination, Annexe 1 of Government Decision 17 January 2008, no. 8.

Hardin, R. (1999). Do We Want Trust in Government? In: Warren, M.E. (Ed.) Democracy and Trust, Cambridge University Press, Cambridge, 22-41.

Hazlett, S.A., Hill, F. (2003). E-government: the Realities of Using IT to Transform the Public Sector, Managing Service Quality, 13(6), 445-452.

Heeks, R., Bailur, S. (2007). Analyzing e-government research: Perspectives, philosophies, theories, methods, and practice, Government Information Quarterly, 24(2), 243-265.

Holland, C.P. (1995). Cooperative Supply Chain Management: The Impact of Interorganizational Information Systems, Journal of Strategic Information Systems, 4(2), 117-133.

Hong, I.B. (2002). A new framework for interorganizational systems based on the linkage of participants' roles, Information and Management, 39(4), 261-270.

Huang, Z., Bwoma, P.O. (2003). An Overview of Critical Issues in E-government, Issues in Information Systems, IV, 164-170.

Håkansson, H. (Ed.). (1982). Int. Marketing and Purchasing of Industrial Goods - An Interaction Approach. IMP Project Group, John Wiley \& Sons, Chichester.

Håkansson, H., Snehota, I. (1989). No business is an island: The network concept of business strategy, Scandinavian Journal of Management, 5(3), 187-200.

Håkansson, H., Snehota, I. (Eds.). (1995). Developing relationships in business networks. Thomson, London.

Irani, Z., Love, P.E.D., Jones, S. (2008). Learning Lessons from Evaluating eGovernment: Reflective Case Experiences that Support Transformational Government, Journal of Strategic Information Systems, 17(2), 155-164.

Irani, Z., Love, P.E.D., Montazemi, A. (2007). E-government: past, present and future, European Journal of Information Systems, 16(2), 103-105.

Karunasena, K., Deng, H., Singh, M. (2011). Measuring the public value of e-government: a case study from Sri Lanka, Transforming Government - People, Process and Policy, 15(1), 81-99.

Kumar, K., H.G. van Dissel (1996). Sustainable Collaboration: Managing Conflict and Cooperation in Interorganizational Systems, MIS Quarterly, 20(3), 279-296.

Melin, U., Axelsson, K. (2009). Managing e-service Development - Comparing two e-Government Case Studies, Journal of Transforming Government - People, Process and Policy, 3(3), 248-270.

Miles, M.B., Huberman, A.M. (1994). Qualitative Data Analysis: A Sourcebook of New Methods. Sage, Newbury Park.

Mintzberg, H (1979). The Structuring of Organizations, Prentice-Hall, Englewood Cliffs, N.J.

Morris, T., Lancaster, Z. (2006). Translating Management Ideas, Organization Studies, 27(2), 207233. 
Myers, M.D. (2009). Qualitative Research in Business \& Management, SAGE Publications, London.

Patton, M.Q. (1980). Qualitative Evaluation Methods, Sage Publications.

Persson, A., Axelsson, K., Melin, U. (2006). e-Government challenges - Exploring interorganisational aspects of e-service development, In: Ljungberg, J., Andersson, M. (Eds.) Proceedings of the $14^{\text {th }}$ European Conference on Information Systems, 1419-1430.

Punia, D.K., Saxena, K.B.C. (2004). Managing inter-organisational workflows in e-government. In: Janssen, M., Sol, H.G., Wagenaar, R.W. (Eds.) Proc. of the $6^{\text {th }}$ Int. Conference on Electronic Commerce (ICEC), 24-26 October, Delft, 500-505.

Robey, D., Im, G., Wareham, J.D. (2008). Theoretical Foundations of Empirical Research on Interorganizational Systems: Assessing Past Contributions and Guiding Future Directions, Journal of the AIS, 9(9), 497-518.

Schedler, K., Summermatter, L. (2007). Customer orientation in electronic government: Motives and effects, Government Information Quarterly, 24, 291-311.

Scholl, H. J. (2006). What can e-Commerce and e-Government learn from each other? In: Proceedings of the 2006 Int. Conference on Digital Government Research (San Diego, Calif., May 21 - 24, 2006). dg.o '06, vol. 151. ACM, New York, NY, 454-455.

Smith, M.L. (2011). Limitations to Building Institutional Trustworthiness through e-government: A Comparative Study of two e-services in Chile, Journal of Information Technology, 26(1), 78-93.

Tambouris E., Wimmer, M.A. (2004). Online one-stop government: a single point of access to public. In: Huang, W. (Ed.) Digital Government: Strategies and Implementations in Developed and Developing Countries, Idea Publ., 115-144.

Tranmüller, R., Wimmer, M.A. (2003). E-government at a decisive moment: sketching a roadmap to excellence. In: Tranmüller, R. (Ed.) EGOV 2003, LNCS 2739, Springer, Berlin, 1-14.

Van de Ven, A. H. (2007). Engaged scholarship: a guide for organizational and social research, Oxford University Press.

Walsham, G. (1995). Interpretive case studies in IS research: nature and method, European Journal of Information Systems, 4(2), 74-81.

Walsham, G. (2006). Doing Interpretive Research, European Journal of Information Systems, 15(3), 320-330.

Webster, J. (1995). Networks of Collaboration or Conflict? Electronic Data Interchange and Power in the Supply Chain, Journal of Strategic Information Systems, August, 31-42.

Yang, J., Papazoglou, M. (2000). Interoperation support for electronic business, Communications of the ACM 43(6), 39-49. 


\section{Appendix}

Interview Guide - an Extract from the G2G Case Study - questions focusing interaction, IS and IOS

\section{Background}

$[\ldots]$

\section{Development Project}

$[.$.

Internal IT-systems and development

Perceptions of the development of the system

Coordination of the project?

Actors in the coordination of the project?

Norms, values, experience in coordinating the project?

Recruitment of project participants?

Project participant skills?

Cooperation and coordination types in the project?

The relationship with external actors (IO perspective) and IOS?

Overall Characteristics

Links

Bonds

Ties

Perceptions about the implementation of the system

Perceptions about training and other preparations for the introduction of the system

Plan for continued development, version control, change requirements, experience, management, etc.

\section{Project - expectations vs. results/outcomes}

Result was expected?

Positive / negative perceptions about the outcome?

Experiences

Perceptions on collaboration with other (external) actors?

Expectations versus outcomes - was as expected / feared?

What effects might this have?

What are the key lessons from this - what advice would you give others in the same situation?

\section{Interpretations of e-services}

$[\ldots]$ 